\title{
A comparative study of student-teacher cognitive abilities and skills on evaluation of academic achievement practices
}

\author{
Shirindokht habibzadeh ${ }^{\mathrm{a}^{*}}$, Sofia heidari kamroudi ${ }^{\mathrm{b}}$, Asieh Ramezany ${ }^{\mathrm{c}}$ and Ashraf alsadat Peyronaziri ${ }^{\mathrm{d}}$
}

${ }^{a} M$ A in Assessment. Coach and faculty member of Farhangian University. Member Assessment of department in Iranian Management System Company (SamaNikan)

${ }^{b} M A$ in Psychology, Coach and faculty member of Farhangian University

${ }^{c} M A$ in Consultation, Coach and faculty member of Farhangian University

${ }^{d} M$ A in Social Sciences, Coach and faculty member of Farhangian University

\section{H R O N I C L E}

Article history:

Received February 12, 2013

Received in revised format

10 May 2013

Accepted 12 May 2013

Available online

May 292013

Keywords:

Elementary schools

Cognitive abilities

Qualitative assessment

\section{Introduction}

During the past few years, there have been some changes on traditional training methodologies in the world, specially, in elementary schools (Erickson, 1985; Polivka et al., 1998). Many schools have decided to perform their assessments in elementary schools based on qualitative methods compared with traditional quantitative techniques (Patton, 1987; Rebok et al., 2001). According to Sarason et al. (1960) anxiety is one of the most influential factors among elementary schools children and one

*Corresponding author. Tel: +989111370788

E-mail addresses: habibzadehshirindokht@yahoo.com (S. Habibzadeh)

(C) 2013 Growing Science Ltd. All rights reserved. doi: $10.5267 /$ j.msl.2013.05.045

\begin{abstract}
During the past few years, there have been some changes on traditional training methodologies in the world, specially, in elementary schools. Many schools have decided to perform their assessments in elementary schools based on qualitative methods compared with traditional quantitative techniques. This paper performs an empirical investigation to find out whether the new evaluation technique has been able to improve student teacher's cognitive abilities and skills on evaluation of academic achievement practices. These student-teacher people taught at elementary schools while they also were studying at university. There are two types of questionnaires: The first one measures cognitive capabilities in four categories including levels of learning and educational objectives, designing paper and pencil test, functional test design and analysis and interpretation of results. The second test is associated with measuring functional skills in the evaluation of academic progress. The information were analyzed based on t-student test as well as two-way analysis of variance. The result of t-statistics was significant only for the last item, analysis and interpretation. In addition, the results of ANOVA test have indicated that there were some differences on cognitive capabilities between two methods of assessments but gender did not make any meaningful difference on functional skills.
\end{abstract}

(C) 2013 Growing Science Ltd. All rights reserved. 
alternative methods for getting rid of anxiety is to change school assessment from traditional to qualitative methods.

Hill and Sarason (1966) investigated the relation of test anxiety and defensiveness to test and school performance over the elementary-school years. Wigfield and Meece (1988) discussed math anxiety in elementary and secondary school students. They used confirmatory factor analyses for two components of math anxiety, a negative affective reactions component and a cognitive component. According to their survey, the influence component of math anxiety related more strongly and negatively than did the worry component to children's ability perceptions, performance perceptions, and math performance.

Shekarey and Sedaghat Rostami (2012) reported that the quality of technical and art schools in Iranian schools could be improved through proper planning for in-service training and through equipping the schools with modern equipment. Analysis and investigation of the internal effectiveness of technical and art schools could also enable the government to plan properly and to reduce unnecessary expenditures.

Taut et al. (2011) addressed the perceived consequences of the Chilean national teacher evaluation system. They interviewed 57 school leaders in 30 schools across 10 municipalities about impacts and implementation of the assessment in their schools. They reported that in the large majority of schools their interviewees observed positive influences such as increased teamwork and internal reflection processes based on the assessment results. In all schools, their interviewees reported on teachers' negative emotions and work overload due to the assessment process, but also about their internalization of the underlying professional standards.

Salisbury (1993) used qualitative research methods to examine practices at an elementary school providing inclusive schooling for students with and without disabilities. The findings indicated that systems change happened slowly, intentionally, and with a cooperative process of decision making which stressed development of policies, conditions, and supported, which were good for all students.

Remesal (2011) presented a specific framework of teachers' conceptions about assessment in school. They stated that results of a qualitative analysis helped building a model of conceptions of assessment. The model included four dimensions about the impacts of assessment on teaching, learning, accountability of teachers and schools to various audiences and stakeholders, and the certification of achievement.

Zand and Ilanlou (2011) investigated the challenges and barriers that qualitative evaluation encountered in Iranian schools. They reported that the main challenge of this project was due to nonpreparation of infrastructures such as proper training, facilities and equipment, and motivation to conduct the project.

Zarrett et al. (2012), in other survey, performed a qualitative study of staff's perspectives on implementing an after school program promoting youth physical activity. Coskun et al. (2011) developed an attitude scale towards multi-grade classrooms (AMC) for elementary school teachers who worked in the Multi-grade Classrooms. Şahin (2008) performed a qualitative assessment of the quality of Turkish elementary schools. Haines et al. (2007) introduced the effects of obesity on learning skills in some elementary schools.

\section{The proposed}

This paper performs an empirical investigation to find out whether the new evaluation technique has been able to improve student-teacher cognitive abilities and skills on evaluation of academic 
achievement practices. These student-teacher employees teach at elementary schools while they also study at university.

There are two types of questionnaires: The first one measures cognitive capabilities in four categories including levels of learning and educational objectives, designing paper and pencil test, functional test design and analysis and interpretation of results. The second test is associated with measuring functional skills in the evaluation of academic progress. The information are analyzed based on $\mathrm{t}$ student test as well as two-way analysis of variance. Table 1 shows details of our survey.

Table 1

The summary of some basic statistics on cognitive capabilities among teacher-student

\begin{tabular}{lcccc}
\hline Background & Evaluation & Mean & Std. dev. & Mean Std. dev. \\
\hline Levels of learning and educational objectives & Qualitative & 4.78 & 1.36 & 0.23 \\
& Traditional & 5.00 & 1.32 & 0.24 \\
\hline Designing paper and pencil test & Qualitative & 5.59 & 1.64 & 0.29 \\
& Traditional & 4.90 & 1.86 & 0.34 \\
\hline Functional test design & Qualitative & 2.75 & 1.36 & 0.24 \\
& Traditional & 2.78 & 0.99 & 0.17 \\
\hline Analysis and interpretation of results & Qualitative & 3.21 & 1.43 & 0.25 \\
& Traditional & 2.33 & 1.47 & 0.25 \\
\hline
\end{tabular}

\section{The results}

In this section, we present details of our findings on testing various hypotheses to learn whether there is any statistical difference between qualitative assessment and traditional evaluation.

\subsection{Testing cognitive skills}

\subsubsection{First hypothesis: Levels of learning and educational objectives}

The first hypothesis examines whether there is any difference between levels of learning and educational objectives between qualitative and traditional methods of assessments or not. In our survey, $\mathrm{t}$-student has been calculated as $(\mathrm{t}=0.62 \mathrm{P}$-value $=0.514, \mathrm{df}=63)$. Therefore, we can conclude that there is no statistical difference between traditional and qualitative methods in term of levels of learning and educational objectives.

\subsubsection{Second hypothesis: Designing paper and pencil test}

The second hypothesis studies whether there is any difference between designing paper and pencil test between qualitative and traditional methods of assessments or not. In our survey, t-student has been calculated as $(\mathrm{t}=0.62 \mathrm{P}$-value $=0.514, \mathrm{df}=63)$. Therefore, we can conclude that there is no statistical difference between traditional and qualitative methods in term of designing paper and pencil test.

\subsubsection{Third hypothesis: Functional test design}

The third hypothesis investigates whether there is any difference between Functional test design between qualitative and traditional methods of assessments or not. In our survey, t-student has been calculated as $(\mathrm{t}=0.497 \mathrm{P}$-value $=0.139, \mathrm{df}=63)$. Therefore, we can conclude that there is no statistical difference between traditional and qualitative methods in term of functional test design. 


\subsubsection{Fourth hypothesis: Analysis and interpretation of results}

The fourth hypothesis investigates whether there is any difference between Analysis and interpretation of results between qualitative and traditional methods of assessments or not. In our survey, $\mathrm{t}$-student has been calculated as $(\mathrm{t}=2.45 \mathrm{P}$-value $=0.017, \mathrm{df}=63)$, which means there is statistically meaningful difference between traditional and qualitative methods in term of analysis and interpretation of results.

Overall, the result of $\mathrm{t}$-student test on four items is equal to $(\mathrm{t}=2.76 \mathrm{P}$-value $=0.08, \mathrm{df}=63)$, which means there is a difference between traditional and qualitative methods in terms of cognitive skills when the level of significance is ten percent. The other interesting issue is to verify whether there is any statistically difference between two assessment methods in terms of cognitive capabilities between two groups. Table 2 demonstrates the summary of the implementation of ANOVA test on these two groups of assessment, qualitative versus traditional.

\section{Table 2}

The summary of ANOVA test on cognitive capabilities

\begin{tabular}{lccccc}
\hline Source of changes & Sum of squares & df & Mean of Squares & F & P-value \\
\hline Evaluation type & 150.843 & 1 & 150.843 & 59.999 & 0.0000 \\
Gender & 0.198 & 1 & 0.198 & 0.079 & 0.78 \\
Evaluation type $\times$ Gender & 0.664 & 1 & 0.664 & 0.264 & 0.609 \\
Error & 153.56 & 61 & & & \\
\hline Sum & 304 & 64 & & & \\
\hline
\end{tabular}

As we can observe from the results of Table 2, there are some differences on cognitive capabilities between two methods of assessment but gender does not make any meaningful difference on functional skills.

\subsection{Testing functional skills}

We have also examined the effects of qualitative versus traditional assessment techniques on functional skills and the results of $\mathrm{t}$-student has been calculated as $(\mathrm{t}=7.84 \mathrm{P}$-value $=0.00, \mathrm{df}=63)$. Therefore, we can conclude that functional skills are statistically different between traditional and qualitative groups. Another interesting issue is to verify whether there is any statistically difference between two assessment methods in terms of functional skills. Table 3 demonstrates the summary of the implementation of ANOVA test on these two groups.

\section{Table 3}

The summary of ANOVA test on functional skills

\begin{tabular}{lccccc}
\hline Source of changes & Sum of squares & df & Mean of Squares & F & P-value \\
\hline Evaluation type & 66.155 & 1 & 66.155 & 7.771 & 0.007 \\
Gender & 26.125 & 1 & 26.125 & 6.93 & 0.23 \\
Evaluation type $\times$ Gender & 3.76 & 1 & 3.76 & 0.43 & 0.51 \\
Error & 523.368 & 61 & & & \\
\hline Sum & 619.938 & 64 & & & \\
\hline
\end{tabular}

As we can observe from the results of Table 2, there are some differences on functional skills between two methods of assessment including qualitative and traditional but gender does not make any meaningful difference on functional skills. 


\section{Conclusion}

In this paper, we have presented an empirical investigation to find the effect of new qualitative assessment against traditional one among some Iranian elementary schools. The proposed study has investigated the effects of cognitive and functional skills between two groups. The survey considered the effect of cognitive skills in four sub categories including levels of learning and educational objectives, designing paper and pencil test, functional test design as well as analysis and interpretation of results based on $t$-student. The result of $t$-statistics was significant only for the last item, analysis and interpretation. In addition, the results of ANOVA test have indicated that there were some differences on cognitive capabilities between two methods of assessments but gender did not make any meaningful difference on functional skills.

\section{Acknowledgment}

The authors would like to thank the anonymous referees for constructive comments on earlier version of this paper.

\section{References}

Coskun, K., Metin, M., Bülbül, M., \& Y1lmaz, G.K. (2011). A study on developing an attitude scale towards multi-grade classrooms for elementary school teachers. Procedia - Social and Behavioral Sciences, 15, 2733-2737.

Erickson, F. (1985). Qualitative methods in research on teaching (pp. 119-62). Institute for Research on Teaching.

Haines, J., Neumark-Sztainer, D., \& Thiel, L. (2007). Addressing weight-related issues in an elementary school: What do students, parents, and school staff recommend?.Eating Disorders, 15(1), 5-21.

Hill, K. T., \& Sarason, S. B. (1966). The relation of test anxiety and defensiveness to test and school performance over the elementary-school years: A further longitudinal study. Monographs of the Society for Research in Child Development, 31(2), 1-76.

Patton, M. Q. (1987). How to use qualitative methods in evaluation (Vol. 4). SAGE Publications, Incorporated.

Polivka, B. J., Lovell, M., \& Smith, B. A. (1998). A qualitative assessment of inner city elementary school children's perceptions of their neighborhood. Public Health Nursing, 15(3), 171-179.

Rebok, G., Riley, A., Forrest, C., Starfield, B., Green, B., Robertson, J., \& Tambor, E. (2001). Elementary school-aged children's reports of their health: a cognitive interviewing study. Quality of Life Research, 10(1), 59-70.

Remesal, A. (2011). Primary and secondary teachers' conceptions of assessment: A qualitative study. Teaching and Teacher Education, 27(2), 472-482.

Şahin, A. E. (2008). A qualitative assessment of the quality of Turkish elementary schools. Eurasian Journal of Educational Research, 30, 117-139.

Salisbury, C. L. (1993). On the nature and change of an inclusive elementary school. Journal of the Association for Persons with Severe Handicaps (JASH),18(2), 75-84.

Sarason, S. B., Davidson, K. S., Lighthall, F. F., Waite, R. R., \& Ruebush, B. K. (1960). Anxiety in elementary school children (Vol. 960). New York: Wiley.

Shekarey, A., \& Sedaghat Rostami, M. (2012). Comparative qualitative assessment of technical and art schools' internal effectiveness: a case study on the schools in Dezful, Iran. Procedia - Social and Behavioral Sciences, 31, 129-132.

Taut, S., Santelices, M.V., Araya, C., \& Manzi, J. (2011). Perceived effects and uses of the national teacher evaluation system in Chilean elementary schools. Studies in Educational Evaluation, $37(4), 218-229$. 
Wigfield, A., \& Meece, J. L. (1988). Math anxiety in elementary and secondary school students. Journal of Educational Psychology, 80(2), 210-216.

Zand, M., \& Ilanlou, M. (2011). Qualitative Evaluation in the Education System of Iran: Challenges and Barriers. Procedia - Social and Behavioral Sciences, 29, 772-779.

Zarrett, N., Skiles, B., Wilson, D.K., \& McClintock, L. (2012). A qualitative study of staff's perspectives on implementing an after school program promoting youth physical activity. Evaluation and Program Planning, 35(3), 417-426. 